\title{
Music and movement: A comparative study between the BAPNE and Suzuki Methods
}

\author{
Elisa De Munari ${ }^{1 a}$, Giorgio Cozzutti ${ }^{1}$, and Francisco Javier Romero-Naranjo ${ }^{2}$ \\ ${ }^{1}$ BAPNE Research Group, via IV Novembre 35, Codroipo 33033, Italy \\ ${ }^{2}$ Departement of Innovation and Didactic Training, University of Alicante, San Vicente del Raspeig \\ s/n 03080 Alicante, Spain DP Sciences, Production Department, 91944 Les Ulis Cedex A, France
}

\begin{abstract}
The aim of this article is to compare the Suzuki and BAPNE methods based on bibliography published for both approaches. In the field of musical and instrumental education and especially for the childhood stage, the correct use of the body and voice are of fundamental importance. These two methods differ from one another; one principally musical and instrumental, which is the Suzuki method, and one non-musical, the BAPNE method, which aims at stimulating attention, concentration, memory and the executing function of the pupil through music and body percussion. Comparing different approaches may provide teachers with a useful insight for facing different issues related to their discipline.
\end{abstract}

\section{Introduction}

In the field of music teaching the comparison between different methodologies takes up great importance. New teaching strategies and contributions can be found through the knowledge of different musical methods and their comparison, highlighting their pros and cons. Use of movement in music teaching has become, lately, a very important and recognized aspect for the dynamism and the contribution in terms of involvement in learning which it may offer. The BAPNE and the SUZUKI methods both have evident elements of connection with the use of movement in learning music. Specifically body percussion offers elements of considerable educational interest [13]. The author has attended the Suzuki rhythm education courses and since 2011 has been teaching this method in various schools. She has also attended the Suzuki contrabass education courses and since 2013 has been teaching for this instrument following this method. Since 2014 she has been attending the BAPNE education courses.

\footnotetext{
${ }^{a}$ Corresponding author: elisademunari@hotmail.com
} 


\section{Methods and Results}

For comparison purposes the author has made use of the model provided by the article by Ana Lucia Frega and by Giorgio Cozzutti [1]. The parameters analyzed are various, among which the most relevant are: use of harmony and melody, use of the body, flow, laterality, creativity. These parameters therefore also include aspects which are not only musical, to gain a broader view of both methods. At the moment there are no comparative studies on Bapne and Suzuki methods.

In the Suzuki method there are some aspects which are not taken into consideration by BAPNE. They involve the focused use of musical elements for instrumental preparation and especially aimed at the development of fine mobility. The structure is defined and proceeds from the global, with a predominant use of the body, to the analytic and abstract.

At the same time there are some specific aspects which belong to the BAPNE method which cannot be found in Suzuki: the movement in space associated to singing is systematic and progressive [2] there is a lot of practice in polyrhythmics, work is always developed in a circle layout to allow for greater integration of the participants, cognitive stimulation, which is constant and progressive, is supported by scientific studies. The study on laterality is very present in the BAPNE method.

Table 1. Comparison between the two methods

\begin{tabular}{lll}
\hline Parameter & Suzuki & BAPNE \\
\hline & & $\begin{array}{l}\text { It is based on studies on the psycho-physiological } \\
\text { perspective and psycho-biological of the body } \\
\text { percussion, the cognitive theories and principles } \\
\text { cal Basics }\end{array}$ \\
and techniques of reinforcement and compensation \\
in a conductive view.
\end{tabular}
Aesthetic and classicist period. Aimed at training a position performer, for this reason improvisation is not practiced much.

The method refers to african principles and values. It uses traditional musical material and tends towards self-expression and cognitive stimulation.

Child-sized professional instruments (violin, Materials cello, guitar), use of small rhythmic instruments used to help rhythmic learning, use of the body functional to the instrument. (rhythmic and gestural choreographies)

Musical Tonal, works a lot on colour and dynamics of language sound (forte, piano, vibrato, staccato, legato, and ear intensity, height, duration), on melody, harmony, form, rhythm. The child immediately learns the pieces as a professional performer

Use of The child must memorize everything. Reading is musical only introduced later, rhythmic first and then on notation the pentagram

Suggestion Listening, singing, performance with the

Only the use of the body for the majority of the activities.

The method does not contemplate the learning of musical language at a generic level, at a specific level it offers strategies for the acquisition of rhythmic values.

Musical notation (rhythmic) is used to help in the conduction of the exercises, in connection with figures of the human body which identify the movements to be carried out. Melodic notation is also present for the songs used.

Listening, singing and movement are always developed in connection with the suggested songs. There is no connection with the musical instrument. 
musical

activities

Curricular structure

The course is very centered on the discipline and the repetition of patterns, modular curriculum
The body is always used in the activities, as percussive instrument and in its movement in space.

The method has strong implications in the cognitive, affective and ability development areas. Education aims at the stimulation of all the cerebral lobes connected with the development of different multiple intelligences postulated by Gardner (1983).

Rhythm is used in a practical way in connection with the movement of the body. It is also present in improvisation.

Melody is used in context with the singing of the songs, there is no specific study of melody.

Harmony is not used since songs are essentially in single voice and the accompaniment of musical instruments is not contemplated.

Imitation, contrary and inverse reaction, signalization in real time, circular variable coordination.

Activities are presented in a very strict and structured way, starting from scientific studies which show the effective psycho-motor abilities based on chronological age.

Reference to flux status (Csikszentmihalyi, 1990) and work in circles and concentric circles with specific reference to the production of hormones such as oxytocin and cortisol in the opposition of different types of work.

There is no specific reference. The method nonetheless is based on specific activities which each teacher develops to maintain and develop the attention of the child

All pieces are learnt by heart. There is no specific

Memory difference between short term memory and long term memory

use of hands and feet combined, alternated, dissociated, differentiation between right hand (arc) and left (instrument) starting from age 3
For each activity the different developed attentions are indicated, sustained alternating and selective.

For each activity the typology of developed memory is indicated, short or long term.

It is constantly developed with specific exercises and games particularly with reference to biomechanical planes and the parietal lobe, especially concerning somatic-sensorial laterality. 


\section{Discussion and Conclusion}

There are some points in common and of difference between the two disciplines which can be elements of integration finalized towards a possible development of single methodologies.

\subsection{Learning process}

The Suzuki method is based on imitation and work is carried out frontally. It may be integrated with the BAPNE method in which 4 different processes of learning are provided: imitation, inverse and reverse reaction, real time signalling and variable circular coordination. The activities in this method are carried out in pairs, double line, circle and double concentric circle.

\subsection{Use of melody-harmony}

In Suzuki the melodic forms are limited to the classical and partially folk repertoire, but always tonal. It is interesting to integrate it with the use of the extraeuropean and modal repertoire carried out in BAPNE (Quarello-Pezzuto-Romero, 2014). In Suzuki work on the education of the musical ear is specifically carried out, both for melody and for harmony, while this does not take place in BAPNE.

\subsection{Laterality}

In BAPNE the two sides of the body are developed harmonically, trying to favour their integration [12]. There is much attention to the personal story of each participant, in respect of their characteristics (left or right-handed). In Suzuki all is taught as right-handed.

\subsection{Use of the body}

In Suzuki melodic and harmonic senses, natural movement and sense of rhythm are developed. Much work is done on fine mobility connected to the use of the instrument motility in connection with the use of the instrument. In BAPNE movement is developed with the objective of polymetric and improvising use in a cognitive, socio-emotional, psycho-motor and neuro-rehabilitating view.

\subsection{Affective-psychological foundations}

Suzuki works on the teacher-mother-son triangle, trying to favour the harmonic development of the relationship. Furthermore with the orchestral lessons there is an attempt to develop the collaborative and cooperative sense of the child. In BAPNE work is done in a group, favouring integration, respect, sense of community.

The Suzuki method is essentially a musical method aimed at teaching instrumental practice, principally based on imitation and on a shared melodic repertoire. The BAPNE method has the objective of cognitive, socio-emotional, psycho-motor and neurorehabilitating stimulation through the use of body percussion and spoken, thought, recited and sung voice. The comparison between these two clearly different methodologies, in goals and modalities may be an interesting instrument of growth drawing lines along which both methods can be developed. 


\section{References}

1. Cozzutti, G., Blessano, E., Romero-Naranjo, F. J., Music, Rhythm and movement: A comparative study between the BAPNE and Willems Methods. Procedia - Social and Behavioral Sciences, Volume 152, 7 October 2014, Pages 1128-18 (2014)

2. Cutrì', D., Crescere suonando. L'educazione musicale nel Metodo Suzuki. Torino: Musica Practica (2014)

3. Doman, G., Che cosa fare per il vostro bambino cerebroleso. Roma: Armando Editore (2009)

4. Enrico, E., Suonare come parlare. Torino: Musica Practica (2007)

5. Freschi, A., Movimento e misura, esperienza didattica del ritmo. Torino: EDT s.r.l. (2006)

6. M.Scaglioso, C., Suonare come parlare: linguaggi e neuroscienze. Roma: Armando Armando (2008).

7. Montessori, M., La formazione dell'uomo. Milano: Garzanti Libri (1993)

8. Romero-Naranjo, F. J. BAPNE: Body percussion, Theoretical practical foundation. Vol 1. Bacelona: Body music - Body percussion Press. (2011a)

9. Romero-Naranjo, F. J. BAPNE: Body percussion, Theoretical practical foundation. Vol 2. Barcelona: Body music - Body percussion Press (2011b)

10. Romero-Naranjo, F. J. BAPNE: Body percussion, Theoretical practical foundation. Vol. 3. Barcelona: Body music - Body percussion Press (2011c)

11. Romero-Naranjo, F. J. BAPNE Method: Foundation Pack 1. 8 DVD-Rom. Barcelona: Body music - Body percussion Press (2011d)

12. Romero-Naranjo, F. J. BAPNE Method: Foundation Pack 2. 8 DVD-Rom. Barcelona: Body music - Body percussion Press (2011e)

13. Romero-Naranjo, F.J. Science \& art of body percussion: A review. Journal of human sport and exercise. North America (2013)

14. Suzuki, S. Crescere con la musica, Milano: Volontè \& Co edizioni (1996) 